BMJ Open Sport \& Exercise Medicine

\section{Objectively quantified physical activity and sedentary behaviour in a young UAE population}

To cite: Dalibalta S, Majdalawieh A, Yousef S, et al. Objectively quantified physical activity and sedentary behaviour in a young UAE population. BMJ Open Sport \& Exercise Medicine 2021;7:e000957. doi:10.1136/ bmjsem-2020-000957

Accepted 3 December 2020
Check for updates

(C) Author(s) (or their employer(s)) 2021. Re-use permitted under CC BY-NC. No commercial re-use. See rights and permissions. Published by BMJ.

'Department of Biology, Chemistry and Environmental Sciences, College of Arts and Sciences, American University of Sharjah, Sharjah, UAE ${ }^{2}$ Institute of Mental Health Sciences, School of Health Sciences, Ulster University, Newtownabbey, UK

${ }^{3}$ Sport and Exercise Sciences Research Institute, Ulster University, Newtownabbey, UK

Correspondence to Dr Sarah Dalibalta; sdalibalta@aus.edu

\section{ABSTRACT}

Objectives There is a lack of public awareness of the importance of engaging in physical activity $(\mathrm{PA})$ in the United Arab Emirates (UAE). Nearly $58 \%$ of the UAE adult population self-reports as being physically inactive although little accelerometer data currently exists. The aim of this study was to obtain the first dataset that objectively quantifies PA and sedentary behaviour (SB) in young UAE adults.

Methods This cross-sectional study recruited 140 university students. Body composition and accelerometry was assessed using a Tanita body composition analyser and ActiGraph accelerometer. Differences $(p \leq 0.05)$ between gender (male vs female) and body mass index (normal vs overweight/obese) were determined using independent samples t-tests and $\chi^{2}$ tests for nominal variables.

Results Both males and females spent high amounts of time in SB, encompassing $~ 80 \%$ of waking hours. PA was primarily light intensity (14.1\%), although males spent significantly greater time in moderate-to-vigorous intensity activity. Moreover, $50 \%$ of males compared with $76.6 \%$ of females were classified as sedentary/low active according to daily step counts.

Conclusion Our data provide evidence of high levels of SB among young adults in the UAE with PA being predominantly light intensity, therefore, both $\mathrm{PA}$ and $\mathrm{SB}$ should be carefully monitored in this country.

\section{INTRODUCTION}

Non-communicable diseases are the leading causes of morbidity and mortality. ${ }^{1}$ Lifestyle factors, such as reduced physical activity (PA) and increased sedentary behaviour (SB), are inextricably linked to these diseases. ${ }^{2}$ PA involves any activities which raise energy expenditure $>1.5$ metabolic equivalent of tasks (METs). ${ }^{34}$ Adult PA recommendations advise $\geq 150 \mathrm{~min} /$ week of moderate-vigorous intensity PA (MVPA). ${ }^{5}$ Physically inactive individuals not meeting the $\mathrm{PA}$ recommendations have an elevated risk of disease. ${ }^{6}$ More recently, SB has been distinguished from physical inactivity, and is characterised by very low energy expenditure ( $<1.5$ METs) involving sitting or lying. ${ }^{7}$ Although no definitive SB

\section{What are the new findings?}

Both young females and males in the United Arab Emirates typically spend over 12 hours/day being sedentary, representing over $80 \%$ of their waking day.

- Many individuals exceeded the new recommended physical activity guidelines containing no minimum moderate-to vigorous activity bout lengths while very few individuals met the older obsolete physical activity guidelines requiring moderate-to-vigorous activity to be completed in at least 10 min bouts.

- In terms of daily step count categories, more females versus males were classified as either 'sedentary' or 'low active'.

guidelines exist, evidence suggests $\mathrm{SB}$ is also an independent risk factor. ${ }^{8}$

Although physical inactivity is globally prevalent, ${ }^{9}$ there is a lack of public awareness on the benefits of PA in the United Arab Emirates (UAE). Nearly $58 \%$ of the UAE adult population are physically inactive, ${ }^{10}$ with adult overweight/obesity prevalence $\sim 71 \%$. ${ }^{11}$ Indeed, the UAE has seen huge economic and industrial growth accompanied by considerable lifestyle changes in the last decades. ${ }^{12}$ In 18-24year olds, only $19.1 \%$ of males and $28.6 \%$ of females reported meeting PA recommendations. ${ }^{10} \mathrm{~A}$ meta-analysis in UAE adolescents who self-reported PA revealed that $\sim 75 \%$ had little-to-no involvement in PA. ${ }^{13}$ Current studies which have investigated PA in the UAE have depended on questionnaires which may not fully capture PA. ${ }^{14}$ The main issue with self-reporting is often social desirability bias or sometimes recall bias that may result in over-reporting. Hence, using measurement tools such as accelerometers could generate estimates that are more accurate as they can record intensity and volume of PA, as well as SB and step counts. ${ }^{15}$

Therefore, this study aimed to use accelerometers to objectively quantify PA and SB in a young adult UAE population and explore 
differences in PA and SB between genders and body mass index (BMI) categories.

\section{METHODS}

\section{Participants}

On obtaining ethical approval (IRB 296) and informed consent, a total of 140 students (63 males and 77 females) attending the American University of Sharjah volunteered to participate in this study. Eligibility criteria included: students aged $\geq 17$ years old; no underlying medical conditions which may interfere with the study design (eg, ambulatory, cardiac or muscle issues); and being able to provide written informed consent. This cross-sectional study took place from September 2016 to March 2018 to account for seasonal variation in the UAE and included students from various ethnic backgrounds, primarily of Arab descent. There was no limit on gender or minority status.

\section{Data collection}

Participants had their body composition analysed using a segmental body composition analyser device (Tanita, Japan). Students then wore an ActiGraph accelerometer (wGT3X-BT, Pensacola, Florida, USA) around the waist on the right side, 24 hours/day for seven consecutive days. Monitors were removed for any water-based activity. Collected data were compiled and stratified based on gender and BMI.

\section{Measurements}

The body composition analyser provided measures of weight, body fat and muscle mass. A cut-off value $<25.0 \mathrm{~kg} / \mathrm{m}^{2}$ was considered 'normal' BMI, $25.0-29.9 \mathrm{~kg}$ / $\mathrm{m}^{2}$ was considered 'overweight' while $\geq 30.0 \mathrm{~kg} / \mathrm{m}^{2}$ was considered 'obese'. ${ }^{16}$ The ActiGraph is an activity monitoring device that provides information on PA intensity and SB. ActiLife software V.6.13.3 (ActiGraph Manufacturing Technology, Florida, USA) was used to initialise and download data which captured raw acceleration data at $100 \mathrm{~Hz}$. Data were analysed using $10 \mathrm{~s}$ epochs using the normal filter. Epoch lengths of $10 \mathrm{~s}$ rather than $60 \mathrm{~s}$ were used in order to more accurately capture $\mathrm{PA}$ and $\mathrm{SB} .{ }^{17}$ Accelerometer data were analysed from 7:00 to 23:00 hours to minimise conflation between sleep time and actual SB time; an important issue in some studies. ${ }^{17}$ For inclusion in the analysis, participants needed to wear the ActiGraph $\geq 600 \mathrm{~min} /$ day for four valid days including at least 1 weekend day. ${ }^{18}$ Wear time was identified and non wear time removed using the Choi 2011 algorithm. ${ }^{19}$ Derived accelerometer data included mean daily time and percentage time spent in different intensities (sedentary, light PA and MVPA), axis-1 counts per minute, peak 1 min step counts (ie, greatest number of steps per minute), daily step counts and daily wear time. Matthews sedentary cut-point and the Troiano Adult (2008) activity cut-point thresholds were used to establish the time spent in different intensities. ${ }^{2021}$ Compliance with the new and older bout-based PA guidelines was also highlighted. ${ }^{22}$
Table 1 The averaged body composition parameters compared between males and females as measured using the body composition analyser

\begin{tabular}{lcl}
\hline Variables & Females & Males \\
\hline Number of participants, $\mathbf{n}$ & 70 & 55 \\
\hline Age, mean (SD) & $20.1(1.4)$ & $19.9(1.3)$ \\
\hline Body mass (kg), mean (SD) & $59.8(13.1)^{\star}$ & $\begin{array}{l}81.1 \\
(20.9)\end{array}$ \\
\hline BMI (kg/m ${ }^{2}$ ), mean (SD) & $22.7(4.6)^{\star}$ & $25.3(6.3)$ \\
Muscle mass (kg), mean (SD) & $39.3(5.1)^{\star}$ & $\begin{array}{l}61.6 \\
(10.1)\end{array}$ \\
\hline Fat-free mass (kg), mean (SD) & $41.3(5.4)^{\star}$ & $\begin{array}{l}64.5 \\
(10.6)\end{array}$ \\
\hline Fat mass (kg), mean (SD) & $18.4(9.0)$ & $\begin{array}{l}16.6 \\
(11.6)\end{array}$ \\
\hline Fat percentage (\%), mean (SD) & $29.4(7.9)^{\star}$ & $18.8(7.5)$ \\
\hline
\end{tabular}

${ }^{*} \mathrm{P} \leq 0.05$ between females versus males.

BMI, body mass index; kg, kilogram; $\mathrm{kg} / \mathrm{m}^{2}$, kilogram per square metre; $n$, number; SD, standard deviation.

Participants achieving $\geq 150 \mathrm{~min}$ MVPA/week, considering any bout length, met the new PA guidelines while those achieving $\geq 150 \mathrm{~min}$ MVPA/week in bout lengths $\geq 10$ min met the bout-based PA guidelines. ${ }^{22}$ Daily step count categories included: $<5000$ steps (inactive); 5000 7499 steps (low active); 7500-9999 steps (somewhat active); $10000-12499$ steps (active) and $\geq 12500$ (highly active). ${ }^{23}$

\section{Statistical analysis}

Normality was assessed using skewness and kurtosis, with values within acceptable limits. The means and SD were calculated using SPSS V.25 (IBM) with the gender (male vs female) and BMI (normal vs overweight/obese) differences determined using independent samples t-tests for continuous variables and $\chi^{2}$ tests used for nominal variables (yes/no answers), with significance set at $\mathrm{p} \leq 0.05$. Due to smaller numbers of participants being classified as overweight or obese versus having a normal BMI, a combined overweight/obese BMI group was used in analyses. All values are reported as mean (SD) or number (percentage).

\section{RESULTS}

\section{Body composition analysis}

Seven females and eight males did not provide body composition data, leaving 70 females and 55 males for the related analyses in tables 1 and 2. Mean age was $20 \pm 1.4$ years old and BMI was $22.7 \pm 4.6 \mathrm{~kg} / \mathrm{m}^{2}$ for females and $25.3 \pm 6.3 \mathrm{~kg} / \mathrm{m}^{2}$ for males (table 1 ). Males had significantly higher BMI and muscle mass, whereas females had significantly higher body fat percentage.

\section{Gender comparison}

One participant did not provide valid accelerometer data meaning 139 participants were analysed. Accelerometer 
Table 2 The averaged PA and SB parameters compared between normal and overweight/obese BMI subgroups

\begin{tabular}{|c|c|c|}
\hline Variables & $\begin{array}{l}\text { Normal } \\
\text { BMI group* }\end{array}$ & $\begin{array}{l}\text { Overweight/obese } \\
\text { BMI group }\end{array}$ \\
\hline Number of participants, $n$ & 85 & 39 \\
\hline BMI (kg/m²), mean (SD) & $21.1(2.4) \dagger$ & $29.9(5.7)$ \\
\hline $\begin{array}{l}\text { Fat percentage (\%), mean } \\
\text { (SD) }\end{array}$ & $23.0(7.8) \dagger$ & $29.3(10.5)$ \\
\hline $\begin{array}{l}\text { Time in SB (min/day), mean } \\
\text { (SD) }\end{array}$ & $761.8(56.7)$ & $740.4(66.0)$ \\
\hline $\begin{array}{l}\text { Time in light PA ( } \mathrm{min} / \text { day), } \\
\text { mean (SD) }\end{array}$ & $124.8(34.8)$ & $136.7(38.4)$ \\
\hline $\begin{array}{l}\text { Time in MVPA (min/day), } \\
\text { mean (SD) }\end{array}$ & $40.7(20.3)$ & $46.2(18.7)$ \\
\hline $\begin{array}{l}\% \text { time spent in SB, mean } \\
\text { (SD) }\end{array}$ & $82.1(4.9) \dagger$ & $80.2(5.0)$ \\
\hline $\begin{array}{l}\text { \% time spent in light PA, } \\
\text { mean (SD) }\end{array}$ & $13.4(3.7)$ & $14.8(4.0)$ \\
\hline $\begin{array}{l}\% \text { time spent in MVPA, } \\
\text { mean (SD) }\end{array}$ & $4.4(2.2)$ & $5.0(2.1)$ \\
\hline $\begin{array}{l}\text { Number meeting new PA } \\
\text { guidelines (no MVPA bouts), } \\
\mathrm{n}(\%)\end{array}$ & $72(84.7)$ & $36(92.3)$ \\
\hline $\begin{array}{l}\text { Time in } \geq 10 \text { min MVPA bouts } \\
\text { (min/day), mean (SD) }\end{array}$ & $6.7(8.3)$ & $7.2(10.1)$ \\
\hline $\begin{array}{l}\text { Number meeting bout- } \\
\text { based PA guidelines } \\
\text { ( } \geq 10 \text { min MVPA bouts), } n(\%)\end{array}$ & $5(5.9)$ & $3(7.7)$ \\
\hline $\begin{array}{l}\text { Axis-1 counts per minute, } \\
\text { mean (SD) }\end{array}$ & $243.3(99.3) \dagger$ & $283.8(101.1)$ \\
\hline $\begin{array}{l}\text { Peak } 1 \text { min step counts, } \\
\text { mean (SD) }\end{array}$ & $134.9(17.7)$ & $134.7(17.8)$ \\
\hline $\begin{array}{l}\text { Daily step counts, mean } \\
\text { (SD) }\end{array}$ & $6738(2377)$ & 7005 (2469) \\
\hline
\end{tabular}

Daily step count categories:

\begin{tabular}{lcr}
\hline Sedentary, $\mathrm{n}(\%)$ & $17(20.0)$ & \\
\hline Low active, $\mathrm{n}(\%)$ & $40(47.1)$ & \\
\hline Somewhat active, $\mathrm{n}(\%)$ & $19(22.4)$ & \\
\hline Active, $\mathrm{n}(\%)$ & $7(8.2)$ & $2(5.1)$ \\
\hline Highly active, $\mathrm{n}(\%)$ & $2(2.4)$ & $923.2(56.4)$ \\
$\begin{array}{l}\text { Wear time (min/day), mean } \\
\text { (SD) }\end{array}$ & $927.3(38.2)$ & \\
\hline
\end{tabular}

*One participant did not provide valid accelerometer data meaning 85 participants with normal BMI were analysed for their accelerometer data.

$\dagger \mathrm{P} \leq 0.05$ between normal $\mathrm{BMI}$ and overweight/obese BMI groups. $\mathrm{BMI}$, body mass index; $\mathrm{kg} / \mathrm{m}^{2}$, kilogram per square metre; MVPA, moderate-vigorous physical activity; $n$, number; PA, physical activity; $\mathrm{SB}$, sedentary behaviour; ;SD, standard deviation.

wear time in both groups was almost 15.5 hour per day. There were no significant differences between gender for any of the SB and light PA parameters; females and males typically spent $>12$ hours/day being sedentary $(>80 \%$ waking hours) while light PA was typically completed for $>2$ hours/day ( $>14 \%$ waking hours) (table 3 ). However, males had significantly higher mean percentage time in MVPA compared with females $(5.5 \pm 2.4 \%$ vs $4.0 \pm 1.6 \%$,
Table 3 The averaged PA and SB parameters compared between males and females as measured using the accelerometer

\begin{tabular}{|c|c|c|}
\hline Variables & Females & Males* \\
\hline Number of participants, $n$ & 77 & 62 \\
\hline $\begin{array}{l}\text { Time in SB (min/day), mean } \\
\text { (SD) }\end{array}$ & $758.9(49.8)$ & $745.1(69.6)$ \\
\hline $\begin{array}{l}\text { Time in light PA (min/day), } \\
\text { mean (SD) }\end{array}$ & $130.0(34.8)$ & $131.2(38.2)$ \\
\hline $\begin{array}{l}\text { Time in MVPA (min/day), } \\
\text { mean (SD) }\end{array}$ & $37.1(14.7) \dagger$ & $50.9(22.0)$ \\
\hline $\begin{array}{l}\% \text { time spent in SB, mean } \\
\text { (SD) }\end{array}$ & $82.0(4.6)$ & $80.3(5.3)$ \\
\hline $\begin{array}{l}\% \text { time spent in light PA, } \\
\text { mean (SD) }\end{array}$ & $14.0(3.7)$ & $14.2(4.0)$ \\
\hline $\begin{array}{l}\text { \% time spent in MVPA, } \\
\text { mean (SD) }\end{array}$ & $4.0(1.6) \dagger$ & $5.5(2.4)$ \\
\hline $\begin{array}{l}\text { Number meeting new PA } \\
\text { guidelines (no MVPA bouts), } \\
\mathrm{n}(\%)\end{array}$ & $64(83.1) \dagger$ & $59(95.2)$ \\
\hline $\begin{array}{l}\text { Time in } \geq 10 \text { min MVPA bouts } \\
\text { (min/day), mean (SD) }\end{array}$ & $5.3(6.1) \dagger$ & $9.2(10.9)$ \\
\hline $\begin{array}{l}\text { Number meeting bout- } \\
\text { based PA guidelines } \\
\text { ( } \geq 10 \text { min MVPA bouts), } n(\%)\end{array}$ & $1(1.3) \dagger$ & 8 (12.9) \\
\hline $\begin{array}{l}\text { Axis-1 counts per minute, } \\
\text { mean (SD) }\end{array}$ & $230.8(77.5) \dagger$ & 297.5 (110.9) \\
\hline $\begin{array}{l}\text { Peak } 1 \text { min step counts, } \\
\text { mean (SD) }\end{array}$ & $135.0(15.6)$ & $135.3(19.9)$ \\
\hline $\begin{array}{l}\text { Daily step counts, mean } \\
\text { (SD) }\end{array}$ & $6300(1722) \dagger$ & $7840(2853)$ \\
\hline \multicolumn{3}{|l|}{ Daily step count categoriest; } \\
\hline Sedentary, n(\%) & $16(20.8)$ & $9(14.5)$ \\
\hline Low active, $\mathrm{n}(\%)$ & $43(55.8)$ & $22(35.5)$ \\
\hline Somewhat active, $\mathrm{n}(\%)$ & $17(22.1)$ & $16(24.2)$ \\
\hline Active, n(\%) & $1(1.3)$ & $11(17.7)$ \\
\hline Highly active, $\mathrm{n}(\%)$ & $0(0.0)$ & $5(8.1)$ \\
\hline $\begin{array}{l}\text { Wear time (min/day), mean } \\
\text { (SD) }\end{array}$ & $926.0(35.1)$ & $927.2(52.4)$ \\
\hline
\end{tabular}

*One male participant did not provide valid accelerometer data meaning 62 male participants were analysed for their accelerometer data.

$+\mathrm{P} \leq 0.05$ between females versus males.

.MVPA, moderate-vigorous physical activity; $n$, number; PA, physical activity; SB, sedentary behaviour; ; SD, standard deviation.

$\mathrm{p}<0.001)$. The percentage of females meeting the new recommended PA guidelines was lower compared with males $(83.1 \%$ vs $95.2 \%, \mathrm{p}=0.03)$ but numbers achieving the new PA guidelines were still high. Few individuals met the bout-based PA guidelines (ie, $1 \%$ females vs $13 \%$ males). Males completed significantly more accelerometer counts per minute compared with females $(297.5 \pm 110.9$ vs $230.8 \pm 77.5)$ counts per minute; $p<0.001)$, and 1540 higher daily steps $(7840 \pm 2853$ steps in males vs $6300 \pm 1722$ steps in females; $\mathrm{p}<0.001)$. For daily step categories, $76.6 \%$ females vs $50.0 \%$ males were classified as sedentary or low active. 


\section{BMI category comparison}

Accelerometer wear time in both groups was almost 15.5 hour per day. There were no significant differences for most PA and SB parameters (table 2). However, percentage time in SB was significantly higher in the normal BMI versus overweight/obese participants $(82.1 \pm 4.9 \%$ vs $80.2 \pm 5.0 \% ; \mathrm{p}=0.04)$ and accelerometer counts per minute were significantly lower in the normal weight versus overweight/obese participants $(243.3 \pm 99.3$ vs $283.8 \pm 101.1$ counts per minute; $p=0.04$ ). There were no significant differences between BMI categories for participants achieving the 'somewhat active' step count classification (ie, $\geq 7500$ daily steps).

\section{DISCUSSION}

The main findings indicate that regardless of gender and BMI category, many young adults in the UAE are sedentary for $\sim 80 \%$ of waking hours while most PA was light intensity. These SB levels are much higher than a suggested maximum of 7 hours/day. ${ }^{24}$ Although there are no clear SB guidelines, this proportion of the day spent being sedentary is much higher than recorded in other studies: $55 \%$ among American adults, ${ }^{20} 69 \%$ among Canadian adults $^{25}$ and $61 \%$ among Nigerian university students. ${ }^{26}$ Compliance with PA guidelines varied greatly depending on the recommendations used and this is certainly an important issue for future studies to consider when assessing compliance with PA guidelines. Many met the new PA guidelines which recommend $\geq 150$ min MVPA/ week accumulated in any bout length while few met the now obsolete bout-based PA guidelines which additionally required MVPA to be completed in $\geq 10 \mathrm{~min}$ bouts. This makes comparison with previous research difficult. Previous findings from Gulf Cooperation Council countries reported that only $40 \%$ of males and $27 \%$ of females achieved the bout-based PA recommendations. ${ }^{27}$ Another study found significantly less Emirati girls engaged in MVPA compared with Emirati males (53\%-63\% vs $77 \%-81 \%) .{ }^{28}$ Research incorporating females from the UAE University found $48.5 \%$ reported not participating in any PA while $47.1 \%$ participated in mild PA. ${ }^{29}$ It is plausible that the desert climate does not support outdoor PA engagement for much of the year. Additionally, the dusty nature of the UAE means high prevalence of respiratory conditions among adolescents, ${ }^{30}$ which can discourage exercise and being outdoors.

Males had higher daily steps than females with $41.9 \%$ of males compared with $23.4 \%$ of females being classified as at least somewhat active (ie, $\geq 7500$ steps/day); levels known to be beneficial for health. ${ }^{22}$ Cultural and societal barriers negatively affect PA engagement in females more so than males. These include the need to preserve modesty, a lack of peer role models and family support, along with increased wealth resulting in the proliferation of household helpers, contributing to decreased PA opportunities. $^{31}$

\section{Limitations and strengths}

Limitations include using a cross-sectional design which incorporated a sub-population of young UAE adults attending university. Additionally, potential covariates such as quality of life, socioeconomic status and aerobic fitness were not collected. This would have facilitated linear regression analyses to identify variables associated with PA and SB in this population. There may be possible selection bias with generally healthier students and possibly more sports-orientated students keen to volunteer. Although common non-wear criteria and cut-points were used, using $100 \mathrm{~Hz}$ (most studies record accelerometry using $30 \mathrm{~Hz}$ ) and the additional methods which had to be applied to separate waking hours from sleep time may affect the comparability of our data to previously published studies. Study strengths include being the first objectively quantified PA and SB dataset within the UAE and obtaining data in a way to account for possible seasonal variation in the UAE.

\section{CONCLUSION}

Our data highlight high levels of SB among young adults in the UAE with PA being predominantly light intensity, therefore, both PA and SB should be carefully monitored across different cohorts in this country. Young UAE females seem to be undertaking less MVPA and daily step counts compared with young UAE males, highlighting the need for researchers and healthcare professionals to develop specific interventions encouraging higher intensity activity in young UAE females. The large discrepancy between those meeting the new PA guidelines compared with those meeting the older bout-based PA guidelines is extremely important for future studies to consider when comparing their adherence data to previous research. Multiple factors may have contributed to these findings meaning the relationships between sociodemographic, cultural and environmental factors need to be more fully understood in order to design effective interventions in this population.

Correction notice This article has been corrected since it first published. The provenance and peer review statement has been included.

Twitter Jason J Wilson @JJW_Research

Acknowledgements The authors would like to acknowledge the American University of Sharjah for funding this project, and all the students who volunteered to take part in the study. The authors also acknowledge the support by the 0pen Access Program from the American University of Sharjah. This paper represents the opinions of the authors and does not mean to represent the position or opinions of the American University of Sharjah

Contributors SD and GD initiated and designed the study and along with SY, drafted the original manuscript. SD, AM, SY and MG were involved with data collection and were responsible for the integrity of the data and accuracy of data analysis. JW and MT processed the accelerometry data, conducted the data analysis and helped draft the original manuscript. All authors carried out critical revisions of the manuscript for intellectual concept and have read and approved the final version of the manuscript and agreed with the order of presentation of the authors.

Funding Authors are thankful to the American University of Sharjah for funding this work (Grant\#: FRG17-R-10). 
Disclaimer The funding body was not involved in the design of the study or analysis, nor in the interpretation of data or writing of the manuscript.

Competing interests None declared.

Patient consent for publication Not required.

Ethics approval Ethical approval was obtained from the ethics committee at the American University of Sharjah. The committee's reference number is IRB 296. Signed informed consent was also obtained from every student who volunteered to participate in this study.

Provenance and peer review Not commissioned; externally peer reviewed.

Open access This is an open access article distributed in accordance with the Creative Commons Attribution Non Commercial (CC BY-NC 4.0) license, which permits others to distribute, remix, adapt, build upon this work non-commercially, and license their derivative works on different terms, provided the original work is properly cited, appropriate credit is given, any changes made indicated, and the use is non-commercial. See: http://creativecommons.org/licenses/by-nc/4.0/.

ORCID iD

Sarah Dalibalta http://orcid.org/0000-0003-2288-9210

\section{REFERENCES}

1 World Health Organization (WHO). Non-communicable diseases. [Internet]. Geneva: World Health Organization, 2018a. Available: http://www.who.int/en/news-room/fact-sheets/detail/ noncommunicable-diseases

2 Baretto PD. Why are we failing to promote physical activity globally?. retrieved from, 2013. Available: http://www.who.int/bulletin/volumes/ 91/6/13-120790.pdf?ua=1

3 World Health Organization (WHO). Physical activity. Geneva: World Health organization, 2018b. Available: http://www.who.int/newsroom/fact-sheets/detail/physical-activity

4 National Heart, Lung and Blood Institute (NIH). Physical activity and your heart. Recommendations for physical activity. [Internet]. Maryland: NIH - National Heart, Lung and Blood Institute, 2017. Available: https://www.nhlbi.nih.gov/health-topics/physical-activityand-your-heart

5 Centers for Disease Control and Prevention CDC. How much physical activity do adults need? [Internet]. Georgia: Centers for Disease Control and Prevention, 2015. Available: https://www.cdc. gov/physicalactivity/basics/adults/index.html

6 Booth FW, Roberts CK, Laye MJ. Lack of exercise is a major cause of chronic diseases. Compr Physiol 2012;2:1143-211.

7 Tremblay MS, Aubert S, Barnes JD, et al. Sedentary Behavior Research Network (SBRN) - Terminology Consensus Project process and outcome. Int J Behav Nutr Phys Act 2017;14:75.

8 Biswas A, Oh PI, Faulkner GE, et al. Sedentary time and its association with risk for disease incidence, mortality, and hospitalization in adults: a systematic review and meta-analysis. Ann Intern Med 2015;162:123-32.

9 World Health Organization (WHO). Global strategy on diet, physical activity and health. Physical activity and adults. [Internet]. Geneva: World Health Organization, 2018d. Available: http://www.who.int/ dietphysicalactivity/factsheet adults/en/

10 Dubai Health Authority (DHA). Dubai household health survey. Preliminary summary of results related to health care financing, 2009. Available: https://www.dsc.gov.ae/Publication/DHA\% 20DHHS\%20Exercise\%20Results\%200ctober\%2010\%202010\% $20 \mathrm{v} 6 \% 20 \mathrm{NEW} \% 20 \mathrm{NUMBERS} \% 20(3)$.pdf
11 World Health Organization (WHO). Diabetes country profiles, 2016. Available: https://www.who.int/diabetes/country-profiles/are_en.pdf

12 International Monetary Fund. World economic outlook database, April 2009: nominal GDP list of countries. 2009. data for the year 2008.

13 Yammine $\mathrm{K}$. The prevalence of physical activity among the young population of UAE: a meta-analysis. Perspect Public Health 2017;137:275-80.

14 Warren JM, Ekelund U, Besson $\mathrm{H}$, et al. Assessment of physical activity - a review of methodologies with reference to epidemiological research: a report of the exercise physiology section of the European Association of Cardiovascular Prevention and Rehabilitation. Eur J Cardiovasc Prev Rehabil 2010;17:127-39.

15 Sylvia LG, Bernstein EE, Hubbard JL, et al. Practical guide to measuring physical activity. J Acad Nutr Diet 2014;114:199-208.

16 World Health Organization (WHO) - Regional Office for Europe. Body mass index- BMI. [Internet]. Copenhagen: World Health Organization - Regional Office for Europe, 2018c. Available: http://www.euro.who. int/en/health-topics/disease-prevention/nutrition/a-healthy-lifestyle/ body-mass-index-bmi

17 Wilson JJ, Skjødt M, McMullan I, et al. Consequences of choosing different settings when processing hip-based accelerometry data from older adults: a practical approach using baseline data from the SITLESS study. J Meas Phys Behav 2020;3:89-99.

18 Migueles $\mathrm{JH}$, Cadenas-Sanchez C, Ekelund U, et al. Accelerometer data collection and processing criteria to assess physical activity and other outcomes: a systematic review and practical considerations. Sports Med 2017;47:1821-45.

19 Choi L, Liu Z, Matthews CE, et al. Validation of accelerometer wear and nonwear time classification algorithm. Med Sci Sports Exerc 2011;43:357-64.

20 Matthews CE, Chen KY, Freedson PS, et al. Amount of time spent in sedentary behaviors in the United States, 2003-2004. Am J Epidemiol 2008;167:875-81.

21 Troiano RP, Berrigan D, Dodd KW, et al. Physical activity in the United States measured by accelerometer. Med Sci Sports Exerc 2008;40:181-8

22 Piercy KL, Troiano RP, Ballard RM, et al. The physical activity guidelines for Americans. JAMA 2018;320:2020-8.

23 Tudor-Locke C, Hatano Y, Pangrazi RP, et al. Revisiting "how many steps are enough?". Med Sci Sports Exerc 2008;40:S537-43.

24 Chau JY, Grunseit AC, Chey T, et al. Daily sitting time and all-cause mortality: a meta-analysis. PLoS One 2013;8:e80000.

25 Colley RC, Garriguet D, Janssen I, et al. Physical activity of Canadian adults: accelerometer results from the 2007 to 2009 Canadian health measures survey. Health Rep 2011;22:7-14.

26 Oyeyemi AL, Muhammed S, Oyeyemi AY, et al. Patterns of objectively assessed physical activity and sedentary time: are Nigerian health professional students complying with public health guidelines? PLoS One 2017;12:0190124.

27 Mabry RM, Reeves MM, Eakin EG, et al. Evidence of physical activity participation among men and women in the countries of the Gulf cooperation Council: a review. Obes Rev 2010;11:457-64.

$28 \mathrm{Ng}$ SW, Zaghloul S, Ali H, et al. Nutrition transition in the United Arab Emirates. Eur J Clin Nutr 2011;65:1328-37.

29 Amine EK, Samy M. Obesity among female university students in the United Arab Emirates. J R Soc Health 1996;116:91-6.

30 Barakat-Haddad C, Zhang S, Siddiqua A, et al. Air quality and respiratory health among adolescents from the United Arab Emirates. J Environ Public Health 2015;2015:1-13.

31 Benjamin K, Donnelly T. Barriers and facilitators influencing the physical activity of Arabic adults: a literature review. Avicenna 2013;2013:8-16. 